\title{
Retroanalytical Study of Epidemiological Factors of Rhinosporidiosis
}

\author{
Sairah Mathew ${ }^{1}$ Ripu Daman Arora ${ }^{2}$ Neel Prabha ${ }^{3} \quad$ Payal Kamble $^{2}$ Satish Suresh Satpute ${ }^{2}$ \\ Nitin M. Nagarkar ${ }^{2}$
}

${ }^{1}$ All India Institute of Medical Sciences, Raipur, Chhattisgarh, India

2 Department of ENT \& HNS, All India Institute of Medical Sciences, Raipur, Chhattisgarh, India

${ }^{3}$ Department of Dermatology, All India Institute of Medical Sciences,

Address for correspondence Ripu Daman Arora, MBBS, MS, MAMS, GE Road, Tatibandh, Raipur, Chhattisgardh, 491099, India (e-mail: neelripu@gmail.com).

Raipur, Chhattisgarh, India

Int Arch Otorhinolaryngol 2021;25(4):e504-e508.

\begin{abstract}
Keywords

- rhinosporidiosis

- epidemiology

- host factors

Introduction Rhinosporidiosis is a granulomatous disease of humans and animals that is caused by Rhinosporidium Seeberi. This disease is endemic in certain states of India, like Chhattisgarh, Tamil Nadu, Kerala, Orissa, and eastern Madhya Pradesh. We conducted a retrospective, record-based study in the department of ENT \& Head and Neck Surgery of a tertiary case institute in Chhattisgarh.

Objective To study the epidemiology of rhinosporidiosis, especially host risk factors. Methods We conducted a retrospective, record-based study in the department of ENT \& Head and Neck Surgery of a tertiary case institute in Chhattisgarh, India. A total of 55 histologically proven rhinosporidiosis patients who were surgically treated in the department over a period of 2 years from November 2014 to November 2016 were included.

Results This study involved 55 histologically proven rhinosporidiosis cases. There were $87 \%$ males and $12 \%$ females. Most of the cases belonged to lower socioeconomic status (92.73\%). All the cases had history of pond bathing. Of 55 cases, 27 cases (49.09\%) had O+ blood group followed by $A+$ in 10 (18.18\%), $B+$ in 9 (16.36) and $A B+$ in 9 (16.36\%). Conclusion The results of the study showed that the disease was associated with the male gender, young and middle age, low socioeconomic status, rural background, pond bathing and $\mathrm{O}+$ blood group.
\end{abstract}

\section{Introduction}

Rhinosporidiosis is a granulomatous disease of humans and animals that is caused by Rhinosporidium Seeberi. This disease is endemic in certain states of India, such as Chhattisgarh, Tamil Nadu, Kerala, Orissa, and eastern Madhya Pradesh. The taxonomy of this organism has always been controversial. Now, it is regarded as an aquatic member of the Protista. ${ }^{1}$

The disease is transmitted to humans through direct contact with spores of the organism, infected fingers or clothes, and pond bathing. The organism mainly targets the mucous membrane of the nasal cavity and nasopharynx. Other uncommon sites are conjunctiva, oral mucosa, epiglottis, trachea, larynx, external genitalia, urethra, rectum, bone, and skin. ${ }^{2-5}$

Four clinical forms of rhinosporidiosis have been described: nasal, ocular, cutaneous, and disseminated form. Classical lesion of rhinosporidiosis is pedunculated or sessile polypoid mass. In humans, $R$. Seeberi triggers the immune mechanism; however, it evades host's immunity through immune suppression, received

May 22, 2020

accepted

August 5, 2020

published online

November 30, 2020
DOI https://doi.org/ 10.1055/s-0040-1718526. ISSN 1809-9777.

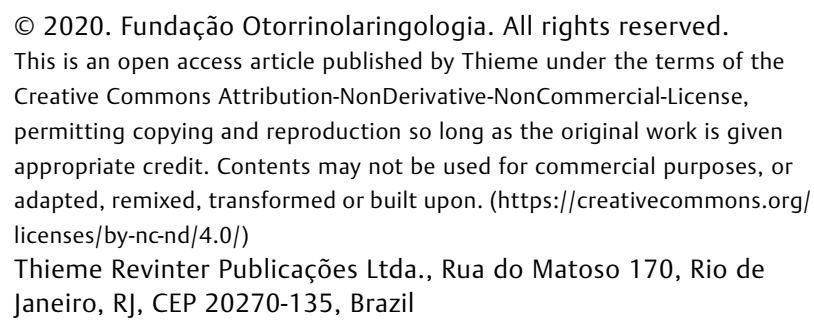


immune distraction, immune deviation, and binding of host immunoglobulins, which might explain certain aspects of the disease, such as chronicity, recurrence and dissemination., 6

Rhinosporidium Seeberi cannot be grown in the culture media. Histopathology of the lesion is the gold standard for diagnosis. ${ }^{8}$ In biopsy, sporangia of various sizes containing endospores in various stages of maturation are seen. The sporangia and endospores can be stained with Gomorimethenamine silver (GMS), mucicarmine, periodic acid Schiff (PAS), Grocott's and hematoxylin \& eosin stain. ${ }^{9}$

Wide local excision of the lesion followed by cauterization of the base is the treatment of choice for rhinosporidiosis. The newer treatment modalities include lasers, harmonic scalpel and coblation. Though chemotherapy is found to be unsuccessful, dapsone has been found to be effective in this disease. ${ }^{10}$

Though many studies have been conducted on this disease, very few have shed light on host risk factors and the role of public health education in the prevention of this disease. As the disease takes a chronic course with recurrence, and Chhattisgarh having a high burden of this disease, the current study was conducted to study the epidemiology of the disease, especially host risk factors. Also, we aimed to identify the regions and tribal belts of Central India with large disease burden so that further preventive measures can be suggested.

\section{Methods}

We conducted a retrospective, record-based study in the department of ENT \& Head and Neck Surgery of a tertiary case institute of Chhattisgarh, India. A total of 55 histologically proven rhinosporidiosis patients who were surgically treated in the department over a period of 2 years from November 2014 to November 2016 were included after getting approval from the ethics committee of the institute. Records of all patients were retrieved from hospital case records and detailed history was recorded in a predesigned proforma. The updated BG Prasad scale was used for analyzing the patients' socioeconomic status. ${ }^{11}$ The records revealed that all patients underwent a detailed clinical history and examination and were thoroughly investigated (routine blood investigations, plain X-ray nose \& para nasal sinuses, computed tomography of paranasal sinuses, nasal endoscopy and biopsy). Surgical excision and electrodessication of the base of the lesion was performed in all patients under general anesthesia. All nasal and nasopharyngeal lesions were operated using nasal endoscopes and powered instruments, like microdebrider and coblator. All excised specimens were sent for histopathological examination. The obtained data were collected, complied, and analyzed. Analysis of the data was done with the help of the statistical software IBM SPSS Statistics for Windows, Version 19.0. (IBM Corp., Armonk, NY, USA).

\section{Result}

The present study involved 55 histologically proven rhinosporidiosis cases, who were surgically treated. Forty-eight
Table 1 Age distribution of patients with rhinosporidiosis

\begin{tabular}{|l|l|l|}
\hline $\begin{array}{l}\text { Age group } \\
\text { (years) }\end{array}$ & $\begin{array}{l}\text { Number } \\
\text { of cases }\end{array}$ & Percentage (\%) \\
\hline$<10$ & 6 & 10.92 \\
\hline $11-20$ & 20 & 36.36 \\
\hline $21-30$ & 17 & 30.91 \\
\hline $31-40$ & 3 & 5.45 \\
\hline $41-50$ & 4 & 7.27 \\
\hline $51-60$ & 1 & 1.82 \\
\hline $61-70$ & 4 & 7.27 \\
\hline Total & 55 & 100 \\
\hline
\end{tabular}

(87.27\%) patients were male and 7 (12.73\%) patients were female. The mean age was 25.17 years ranging from 6 to 70 years. The most common age group was 11 to 30 years, with 37 patients [-Table 1]. Of 55 cases, 24 (43.64\%) were students, followed by laborers $(18,32.73 \%)$, housewife ( 7 ; $12.73 \%)$ and others $(6,10.91 \%)$. The majority of the cases ( 45 cases, $81.82 \%)$ were residing in rural areas followed by semiurban (6 cases, $10.91 \%$ ) \& urban areas ( 4 cases, $7.27 \%$ ). Most of the cases belonged to lower socioeconomic status (92.73\%), followed by middle socioeconomic status (7.27\%). All the cases had history of pond bathing.

The most common symptom of the disease was nasal obstruction (43.67\%) followed by epistaxis (23.67\%). The symptoms of the disease are mentioned in - Table 2. Of the 55 cases, 45 (81.81\%) were of primary rhinosporidiosis and $10(18.18 \%)$ were of recurrent rhinosporidiosis. Both right $(22 ; 40 \%)$ and left $(23 ; 41.82 \%)$ sides of the nasal cavity were affected almost equally. Bilateral nasal involvement was seen in 3 cases (5.45\%), pharynx in 6 (10.90\%), and larynx in $1(1.82 \%)$. The most affected site was the nasal cavity (87.27\%), followed by the nasopharynx (10.91\%) (-Fig. 1, - Fig. 2). The site of attachment of the mass in the nasal cavity was the inferior turbinate and floor in 19 cases (34.55\%), followed by the nasal septum, in 16 cases (29.09\%), multiple sites in 6 cases $(10.90 \%)$, pharynx in 6 cases (10.90\%), lateral wall in 5 cases (9.09\%), inferior meatus \& nasolacrimal duct in 2 cases (3.64\%), and larynx in 1 case

Table 2 Symptoms of patients with rhinosporidiosis

\begin{tabular}{|l|l|l|}
\hline Symptom & $\begin{array}{l}\text { Number of } \\
\text { cases }\end{array}$ & Percentage (\%) \\
\hline Nasal obstruction & 24 & 43.67 \\
\hline Epistaxis & 13 & 23.67 \\
\hline Nasal mass & 5 & 9.09 \\
\hline Nasal discharge & 5 & 9.09 \\
\hline Breathing difficulty & 4 & 7.27 \\
\hline Voice change & 2 & 3.64 \\
\hline Foreign body sensation & 2 & 3.64 \\
\hline Total & 55 & 100 \\
\hline
\end{tabular}




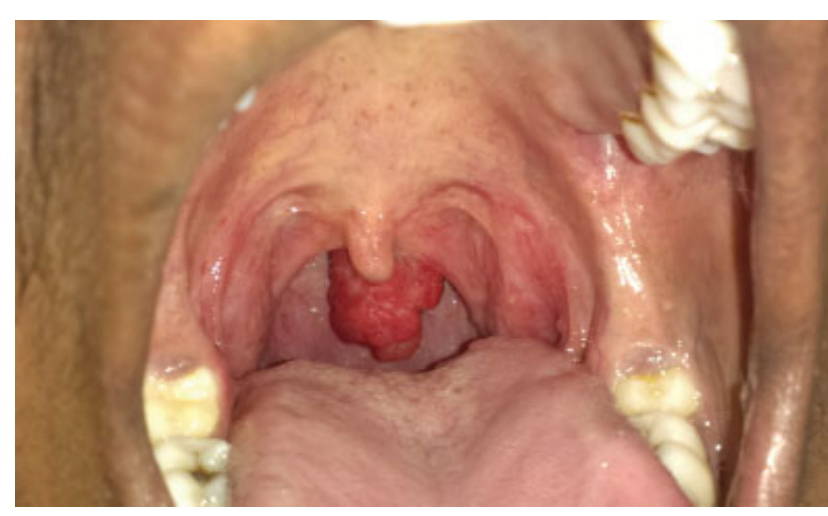

Fig. 1 Naso-oropharyngeal rhinosporidiosis.

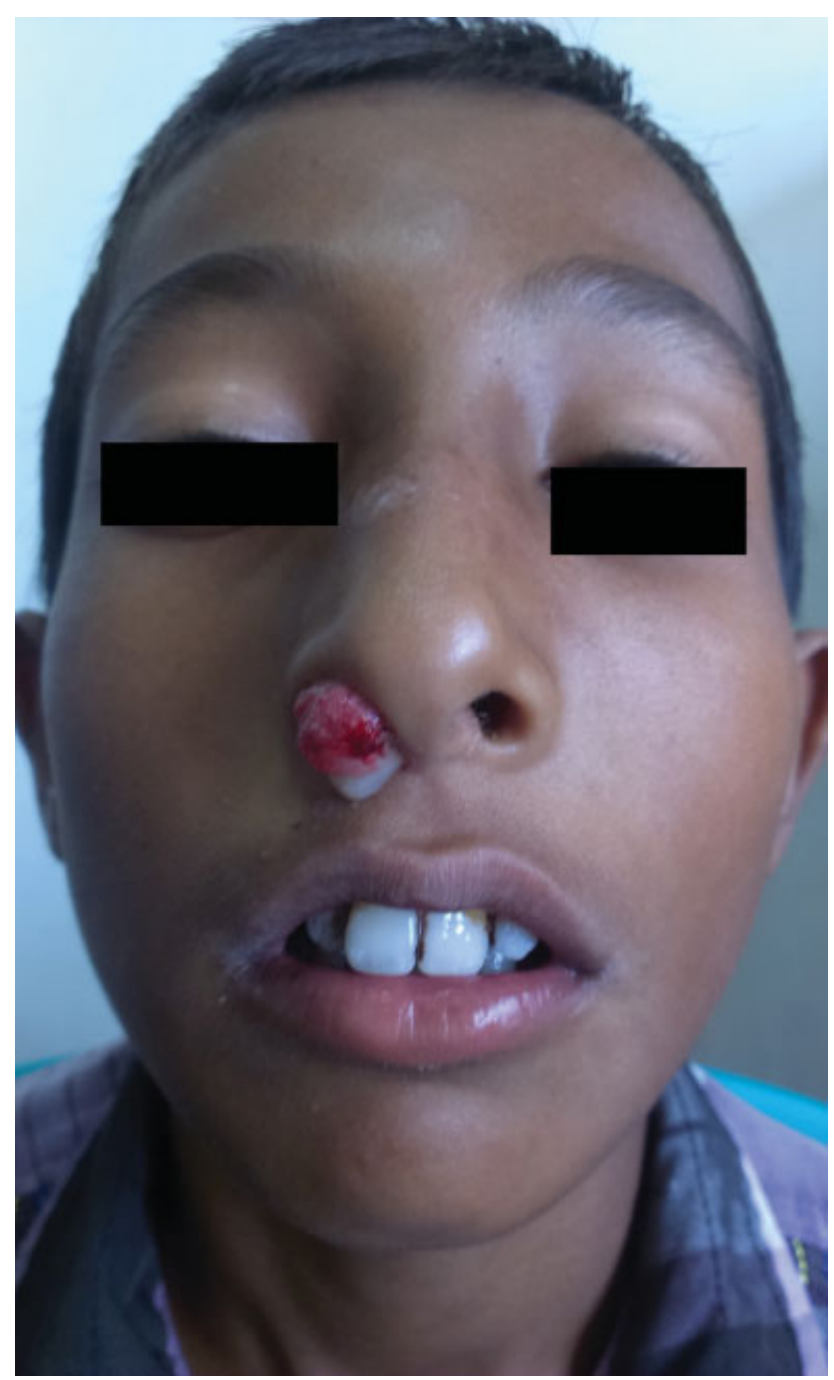

Fig. 2 Nasal rhinosporidiosis.

(1.82\%). Of 55 cases, 27 (49.09\%) had $\mathrm{O}+$ blood group, followed by $\mathrm{A}+$ in 10 (18.18\%), $\mathrm{B}+$ in 9 (16.36), and $\mathrm{AB}+$ in 9 (16.36\%). Of the 10 cases of recurrence, most of them had O+ blood group $(7,70 \%)$. However, this difference was not statistically significant ( $p$-value $=0.49$ ). The patients were from different districts of Chhattisgarh, the maximum burden of disease was found in the Raipur district, where the
Table 3 District-wise distribution of rhinosporidiosis in Chhattisgarh

\begin{tabular}{|l|l|l|}
\hline District & Number of cases & Percentage (\%) \\
\hline Raipur & 26 & 47.27 \\
\hline Durg & 11 & 20 \\
\hline Baloda Bazar & 7 & 12.72 \\
\hline Mahasamund & 3 & 5.45 \\
\hline Bemetra & 2 & 3.64 \\
\hline Raigarh & 2 & 3.64 \\
\hline Jangir & 1 & 1.82 \\
\hline Balod & 1 & 1.82 \\
\hline Dhamtari & 1 & 1.82 \\
\hline Rajnandgaon & 1 & 1.82 \\
\hline Total & 55 & 100 \\
\hline
\end{tabular}

facility is located, followed by Durg (- Table 3). The district of Raipur was with maximum case load (47.27\%).

\section{Discussion}

In the present study, rhinosporidiosis was seen more frequently in males as compared with females (M:F 6.86:1). In the literature, the ratio of male to female incidence of this disease varies from $1.3: 1$ to $9: 1 .^{9,12-15}$ A few studies have shown female predominance also. ${ }^{16}$ The reason for the lower number of females affected might be less frequent pond baths. Some authors are of the opinion that estrogen may have a protective role. ${ }^{17}$ In the present study the most affected age group was 11 to 30 years $(67.27 \%)$. Sinha et $\mathrm{al}^{9}$ and Manonmany et al ${ }^{14}$ have found that 20 to 40 years was the most affected age group. In a study by Karthikeyan et $\mathrm{al}^{12}, 21$ to 50 years was the most commonly affected age group, with 31 to 40 years age group being even more predominantly affected; however, it was not statistically significant. ${ }^{12}$ Other studies also found that the most affected age group was 21 to 30 years. ${ }^{13-15}$ Hence, we can conclude that mostly young and middle aged persons are affected by rhinosporidiosis.

Most studies have found that farmers, students, and manual laborers were mainly affected by rhinosporidiosis $^{4,12,16,17}$ The disease was found to affect people residing in rural areas, ${ }^{12,15,17-20}$ and some studies show higher incidence in tribal populations. ${ }^{16,21}$ People belonging to lower socioeconomic status were found to be more affected. ${ }^{12,15,17}$ In the current study, the majority of the cases was from rural areas (81.82\%), and most of the affected individuals were students, followed by laborers. The major portion of cases belonged to the lower socioeconomic status. Thus, rhinosporidiosis shows a strong association with rural residential and low socioeconomic status.

Previous studies have found that patients affected with the disease had history of taking baths in ponds, rivers, tanks, lakes, reservoirs, and wells. ${ }^{4,12,15-21}$ All cases in the present study also had history of pond bathing. This shows the constant exposure of the patients to infected water sources. In endemic areas, 
many people take baths in common water bodies; however, few people develop rhinosporidiosis. This indicates that there are some factors in the hosts that predispose them for rhinosporidiosis. To date, blood group is the only predisposing factor of host on which some data are available. Kameswaran et al reported maximum incidence rate of rhinosporidiosis in blood group $\mathrm{O}(70 \%)$, followed by blood group $\mathrm{AB} .{ }^{22}$ However, Jain et al denied the role of blood group as a predisposing factor for rhinosporidiosis. ${ }^{23}$ A study conducted by Sinha et al revealed that the major portion of cases belonged to the $O$ blood group (44\%), followed by the AB group (22\%). ${ }^{9}$ Vadakkan et al reported maximum incidence rate of rhinosporidiosis in the blood group $\mathrm{O}$ (75\%), followed by the blood group A (20\%). ${ }^{24}$ Manonmonyet al concluded that the majority of the cases belonged to the $\mathrm{B}+$, followed by the $\mathrm{O}+$ blood group. ${ }^{18}$ In our study, the highest incidence was seen in the $\mathrm{O}+$ blood group, followed almost equally by $\mathrm{A}+, \mathrm{B}+$, and $\mathrm{AB}+$. Another host factor that needs to be investigated is human leukocyte antigen (HLA) typing.

In the present study, the most common symptom of rhinosporidiosis was nasal obstruction, followed by epistaxis, nasal discharge, and nasal mass. Similar findings were found in other studies. ${ }^{12,25}$ In one study, the most common symptom was epistaxis. ${ }^{15}$ In the current study no predilection to any specific side of nasal cavity was seen, both right and left sides were affected almost equally, whereas Manonmony et al, in their study, found a higher incidence on the right side of the nasal cavity (47\%), followed by left side (33\%). ${ }^{18}$ In the present study, the nasal cavity was the most common site involved, followed by multiple sites, pharynx,

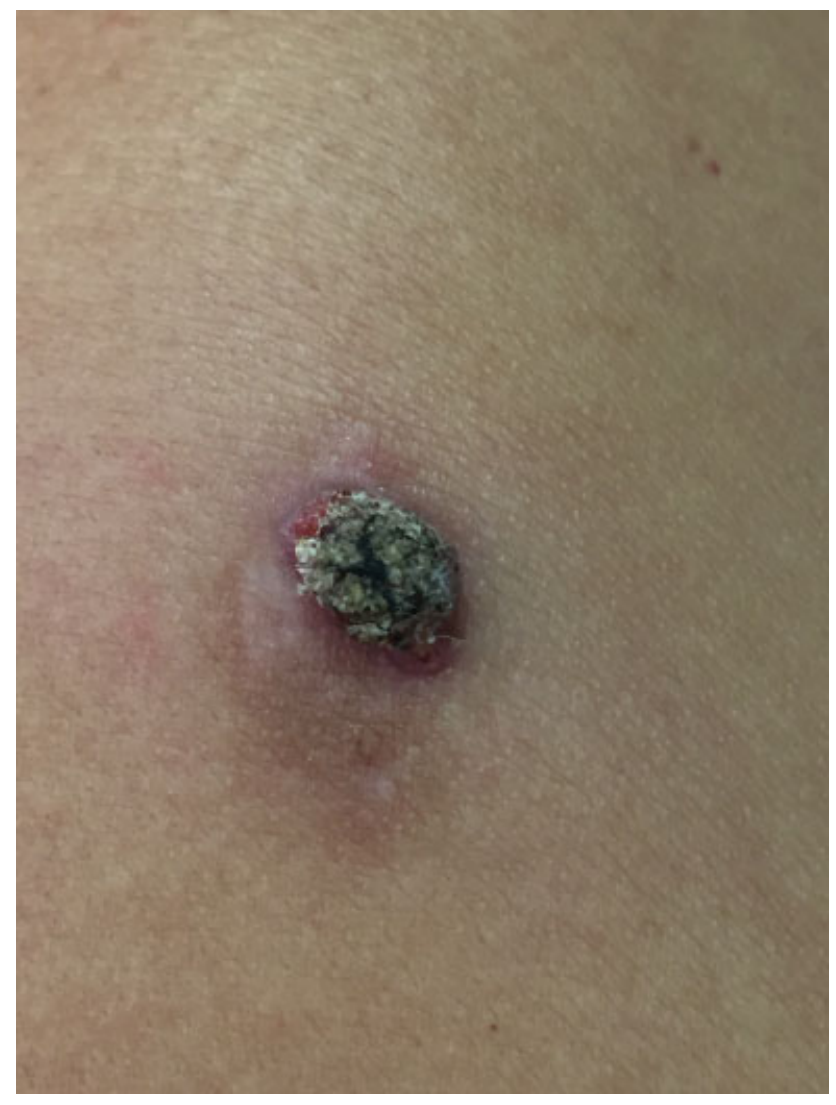

Fig. 3 Cutaneous rhinosporidiosis. and larynx. Among the multiple site involvement, one patient had nasopharyngeal and cutaneous rhinosporidiosis [-Fig.3]. Most other studies have reported that the site most frequently affected was the nasal cavity, followed by the nasopharynx. ${ }^{8,12,15,17,19-21,24,25}$ Manonmony et al $^{18}$ concluded that the most frequently affected site was the nose, followed by the oropharynx. Other sites affected include the larynx, trachea, eyes, skin, bone, penis, nasolacrimal duct, parotid gland, soft palate, and muscles. $8,12,15,19-21,24-26$

In a study of nasal rhinosporidiosis cases by Guru and Pradhan, the lateral wall of the nose, followed by the septum and floor, was the most common site of attachment of the mass. ${ }^{15}$ Karthikeyan et al found the septum, followed by the inferior turbinate and inferior meatus, as the most common site of attachment. ${ }^{12}$ While in our study of nasal rhinosporidiosis cases, the inferior turbinate and floor were the most common sites, followed by the nasal septum and lateral wall.

High chance of recurrence is seen in rhinosporidiosis even after medical and surgical therapy, according to the literature recurrence rate ranges from 5 to $63 \% .^{12}$ Of the 55 cases in the present study, $10(18.18 \%)$ cases were of recurrence. Vadakkan et al, in their study, mentioned a case having 42 episodes of recurrent nasal and nasopharyngeal rhinosporidiosis. ${ }^{24}$ Similarly, in our study, 1 patient had 21 episodes of recurrent nasal and nasopharyngeal rhinosporidiosis.

In the present study, analysis of the distribution of the disease in the Chhattisgarh state of India found that the highest incidence of rhinosporidiosis was in the district of Raipur, followed by Durg. It was also found that the disease was more prevalent in central part of the state when compared with the northern and southern parts. This might be either due to the drainage area of the institute being in the central part of Chhattisgarh or disease may be endemic to central Chhattisgarh.

\section{Conclusion}

Rhinosporidiosis is associated with the male gender, young and middle age group, low socioeconomic status, rural background, pond bathing and blood group $\mathrm{O}+$. Additionally, more studies are required to know the role of other host factors, such as HLA typing and immune system. The disease is chronic with a high recurrence rate. The nasal mucosa is commonly involved, and nasal obstruction is the most common presentation. The first choice of treatment is surgical excision, preferably using endoscope and powered instruments with cauterization of the base. Rhinosporidiosis is more prevalent in the central part of Chhattisgarh. A strong public health education system is required in these endemic areas to prevent this disease.

\section{Conflict of Interests}

The authors have no conflict of interests to declare.

\section{Reference}

1 Fredricks DN, Jolley JA, Lepp PW, Kosek JC, Relman DA. Rhinosporidium seeberi: a human pathogen from a novel group of aquatic protistan parasites. Emerg Infect Dis 2000;6(03):273-282 
2 Rao PN. Rhinosporidiosis of the conjunctiva. J Indian Med Assoc 1962;39:601-602

3 Franca GV Jr, Gomes CC, Sakano E. Altermani Am, Shimizu Lt. Nasal rhinosporidiosis in children. J Pedatr 1994;70:299-301(Rio J)

4 Makannavar JH, Chavan SS. Rhinosporidiosis-a clinicopathological study of 34 cases. Indian J Pathol Microbiol 2001;44(01):17-21

5 Ghorpade A. Giant cutaneous rhinosporidiosis. J Eur Acad Dermatol Venereol 2006;20(01):88-89

6 Herr RA, Mendoza L, Arseculeratne SN, Ajello L. Immunolocalization of an endogenous antigenic material of Rhinosporidium seeberi expressed only during mature sporangial development. FEMS Immunol Med Microbiol 1999;23(03):205-212

7 Jayasekera S, Arseculeratne SN, Atapattu DN, Kumarasiri R, Tilakaratne WM. Cell-mediated immune responses (CMIR) to Rhinosporidium seeberi in mice. Mycopathologia 2001;152(02):69-79

8 Arseculeratne SN. Recent advances in rhinosporidiosis and Rhinosporidium seeberi. Indian J Med Microbiol 2002;20(03): 119-131

9 Sinha A, Phukan JP, Bandyopadhyay G, et al. Clinicopathological study of rhinosporidiosis with special reference to cytodiagnosis. J Cytol 2012;29(04):246-249

10 Arseculeratne SN. Chemotherapy of rhinosporidiosis: A review. J Infect Dis Antimicrob Agents 2009;26:21-27

11 Singh T, Sharma S, Nagesh S. Socio-economic status scales updated for 2017. Int J Res Med Sci 2017;5:3264-3267

12 Karthikeyan P, Vijayasundaram S, Pulimoottil DT. Aretrospective epidemiological study of rhinosporidiosis in a rural tertiary care centre in Pondicherry. J Clin Diagn Res 2016;10(05):MC04-MC08

13 Kutty MK, Sreedharan T, Mathew KT. Some observation on rhinosporidiosis. Am J Med Sci 1963;246:695-701

14 von Haacke NP, Mugliston TA. Rhinosporidiosis. J Laryngol Otol 1982;96(08):743-750

15 Guru RK, Pradhan DK. Rhinosporidiosis with special reference to extra nasal presentation. J Evolution Med Dent Sci 2014; 22:6189-6199
16 Krishna Kumari S, Uma P, Ramesh S, Vasavi HL, Rajani K. Prevalence of rhinosporidiosis in Srikakulam District. J of Evolution of Med and Dent Sci 2015;4:8685-8689

17 Majumdar AB, Biswas D, Paul SS, Ray S, Kumar G. Rhinosporidiosis: a clinicopathological study from a rural tertiary health care centre, Bihar, India. Int J Adv Med 2014;1:213-216

18 Manonmany S, Renjit RE, Philip JT, Raj AR. Rhinosporidiosis: analysis of cases presenting to a tertiary care hospital in rural Kerala. Int J Biomed Res 2015;6:416-420

19 Ratnakar C, Madhavan M, Sankaran V, Veliath AJ, Majumder NK, Rao VA. Rhinosporidiosis in Pondicherry. J Trop Med Hyg 1992;95 (04):280-283

20 Saha SN, Mondai AR, Bera SP, Das S, Banerjee AR. Rhinosporidial infection in west bengal-a calcutta based hospital study. Indian J Otolaryngol Head Neck Surg 2001;53(02):100-104

21 Sengupta S, Pal S, Biswas BK, Jana S, Biswas S, Minz RS. Clinicopathological study of 273 cases of rhinosporidiosis over a period of ten years in a tertiary care institute catering predominantly rural population of tribal origin. Bangladesh Journal of Medical Science 2015;14:159-164

22 Kameswaran S, Lakshmanan M. Rhinosporidiosis. In: Kameswaran S, Kameswaran M, eds. ENT disorders in a tropical environment. Chennai: MERF Publications; 1999:19-34

23 Jain S. Aetiology and incidence of rhinosporidiosis. Indian J Otorhinol 1967;19:1-21

24 Vadakkan JR, Ganshbala A, Jalagandesh B. A clinical study of rhinosporidiosis in rural coastal population: our experience. Journal of Evolution of Medical and Dental Sciences 2014; 3:11938-11942

25 Bandyopadhyay SN, Jana U, Bandyopadhyay G, et al. Rhinosporidiosis: various presentations and different sites. Bengal J Otolaryngol Head Neck Surg 2015;23:48-56

26 Saha J, Basu AJ, Sen I, Sinha R, Bhandari AK, Mondal S. Atypical presentations of rhinosporidiosis: a clinical dilemma? Indian J Otolaryngol Head Neck Surg 2011;63(03):243-246 